Psychological Medicine, 2002, 32, 1339-1343. (C) 2002 Cambridge University Press

DOI: $10.1017 /$ S0033291701004974 Printed in the United Kingdom

\author{
EDITORIAL
}

\title{
Routine outcome assessment in mental health services ${ }^{1}$
}

Measuring and interpreting outcome is more difficult in mental health services than in some other areas of health care, for at least five reasons. First, the effect of the treatment may be to slow decline or to maintain the current level, so the score on the outcome measure itself may not improve (or may even get worse) despite best quality clinical care. Secondly, the best available evidence in the United Kingdom indicates that clinical and social variables predict no more than $30 \%$ of the variance in an individual's quality of life (UK700 Group, 1999). Thirdly, different types of outcome are desynchronous (e.g. Drury et al. 1996), changing at different rates during an intervention. Fourthly, there may not be agreement regarding what is a positive change in outcome - the patient who has fewer episodes of mania as a result of treatment may see this as a negative outcome. Finally, three levels of mental health service can be differentiated: treatment (specific interventions), 'programme (combination of different treatment components); and system (all programmes for a defined target group in a given area) (Burns \& Priebe, 1996). The outcome data needed to evaluate each level will be very different.

The solution to these issues that has evolved in research studies has been to assess a wide range of treatment and programme-level outcomes, from multiple perspectives. For example, the programme-level PRiSM Psychosis Study evaluated two models of community care for people with psychotic diagnoses (Thornicroft et al. 1998). The outcome domains assessed by interviewing the patient were symptomatology, needs, quality of life, services being received (to allow economic analysis), social network and satisfaction with care. The outcome domains assessed by interviewing staff were global level of functioning, needs and social behaviour, and by interviewing carers were their experience of care-giving and their own symptomatology. All interviews were conducted by researchers. In general, most research and evaluation studies take place in 'research contexts where specifically funded and trained external raters parachute into routine clinical settings in order to guarantee the validity and reliability of study measures' (Harrison \& Eaton, 1999, p. 187).

\section{RESEARCH FINDINGS}

This approach has led to the identification of several consistent findings. The most important outcome is quality of life, and the best predictor of quality of life is level of unmet need, which is a better predictor than diagnosis, symptomatology or other social or clinical variables (McCrone \& Strathdee, 1994; Slade et al. 1999 a; UK700 Group, 1999). Staff and patient assessments of need differ, so both should be considered (Sainfort et al. 1996; Slade et al. 1998; Hansson et al. 2001). In this issue Gilbody et al. (2002) review studies of routine administration of quality of life and needs assessment instruments. More generally, outcome should be considered multi-dimensionally, by measuring multiple outcome domains (Biggeri et al. 1996; Clifford, 1998). Process variables are also important. There is a moderate but reliable relationship between alliance as rated by either staff or patient and outcome, and this relationship is not influenced by other moderator variables such as outcome measure or rater, time or type of alliance assessment, type of treatment or publication status of study (Keijsers et al. 2000; Martin et al. 2000). There is also a robust relationship between collaboration in the relationship and medication compliance (Fenton et al. 1997).

\footnotetext{
${ }^{1}$ Address for correspondence: Dr Mike Slade, Health Services Research Department, Institute of Psychiatry, De Crespigny Park, Denmark Hill, London SE5 8AF.
} 
In summary, mental health outcomes research indicates that care should be provided on the basis of need so as to improve quality of life, that attention should be paid to the therapeutic relationship, and that outcome should be considered from more than one perspective. This involves assessing these outcomes in some way. Are outcomes such as quality of life, needs and therapeutic alliance being routinely measured in practice? Examples from the United States, England and Australia will be considered.

\section{CURRENT PRACTICE}

In the United States, the rising costs of mental health care resulted in the rapid introduction of managed care in the 1980s (Dickey \& Azeni, 1992). Initially envisaged as a cost containment procedure and driven to some extent by pressure from health insurance companies, the approach was based on the identification of diagnostic related groups (DRGs), with each DRG being associated with access and benefit levels (i.e. limitations). The failure of the DRG system to result in equity and a fair matching of need with resources has led to this approach being superseded by an emphasis on outcomes rather than diagnosis. However, consideration of needs remains entirely absent, for example not warranting a section in the 820-page Handbook of Psychiatric Measures by the American Psychiatric Association (2000).

In England, active commissioning of mental health services was introduced over the same period, driven by the political perspective that systems work most efficiently when they follow the commercial model of rewarding the matching of supply and demand. The structure of commissioning changed during the decade, moving from District Health Authorities, through to a combination of Health Authority and fund-holding GPs, to the development of Primary Care Groups and Primary Care Trusts. However, the common theme was that service commissioners wanted to ensure that they got what they paid for. Since commissioners pay for structure (e.g. hospitals, mental health staff) and processes (e.g. Mental Health Act assessment, therapy), routinely collected data focused on these aspects. The result was that most if not all data collected for local (commissioner) or national return focused on aspects such as where, when, how often and for how long patients were seen, either in individual meetings or over extended periods ('consultant episodes'). In the late 1990s, a new emphasis on quality and outcome began to emerge.

In Australia, by contrast, the process of consumer involvement in mental health services is more advanced, and substantial efforts have been directed towards considering how outcomes should be monitored at the level of the individual patient. A seminal report by Andrews and colleagues (1994) identified specific outcome measures that should be considered for use in Australian mental health services. These measures were field-tested by an independent research team, resulting in specific recommendations for services (Stedman et al. 1997), with some assessments now used routinely throughout many adult mental health services.

International attempts to assess outcome have focused on informing management decisionmaking at the system level, with an emphasis on the perceived benefits of system-level as opposed to treatment-level outcome indicators.

\section{ROUTINE OUTCOME ASSESSMENT}

The ongoing measurement of treatment-level outcomes in routine mental health service - which will be referred to as routine outcome assessment - could be justified for both ethical and scientific reasons. Ethically, it is important to ensure that the treatment being provided in routine services is of the highest quality, which can only be done by monitoring its impact. Scientifically, although a fair amount is known about the efficacy of a range of treatments (established in research studies), far less is known about the effectiveness or cost-effectiveness of treatments when used in routine mental health services.

It is, therefore, worth considering why routine outcome assessment is currently not undertaken in most mental health services. A number of possible reasons for this have been suggested, including 
lack of appropriate instruments, time and incentives (financial and professional) to offset the costs of monitoring outcome, and lack of expectations from senior staff that junior staff collect outcome data (Huxley, 1998; Marks, 1998; Slade et al. 1999 b; Walter et al. 1998). Purely in terms of the assessment process, there no consensus regarding what outcome domains to include, who to ask when assessing, and what assessment measures to use (Clifford, 1998). Although these difficulties can be addressed, as shown by the Australian developments, clinicians remain in general unconvinced of the benefits of routinely monitoring outcome. The remainder of this editorial will argue that routine outcome assessment has the potential to be of benefit at the treatment level.

\section{BENEFITS FOR PATIENTS}

Emerging evidence suggests that routine outcome assessment has the potential to inform the treatment of individual patients. There is strong evidence that routine outcome assessment results in a beneficial focus on outcome in evaluating treatment approaches (Biggeri et al. 1996; Marks, 1998). Furthermore, there is emerging evidence from trials of cognitive therapy, in which the results of patient-based outcome monitoring are charted over time and shared with the therapist. The rationale for this monitoring is to set up the expectation of change, to reality test the common patient belief that they are making no progress, and to identify if indeed the therapy is working. Many patients benefit from this technique, both in 'feeling heard' and contextualizing the outcome as a 'blip' rather than a downward spiral when the chart indicates deterioration, and in reinforcing change when the chart indicates improvement. From a therapist perspective, the charting of patientbased outcomes can act as a motivator to re-evaluate the treatment plan where no improvement is evident. Such reflection has the potential to improve outcome, either directly (through changing the content of care) or as an effect modifier (by improving process issues).

How can reflective practice be facilitated? Simple feedback to the staff may be insufficient (Simon et al. 2000). One approach would be the routine collection of outcome data from both staff and patient perspectives, and then the routine feedback of these data to staff and patients. Either or both of completing the assessments and receiving the feedback may prompt reflection on the process or the content of care. The potential mechanisms of change for staff involved in such an approach are shown as a testable model in Fig. 1. Equivalent processes can be hypothesized for patients.

\section{IMPLEMENTATION STRATEGIES}

How should services wishing to implement routine outcome assessment proceed? The approach of measuring every plausible outcome from each relevant perspective cannot be directly transferred for at least three reasons. First, it requires the use of resources (e.g. interviewer time) which, while possible for efficacy studies, are unlikely to be available in routine services. Monitoring even a small number of outcome domains in routine practice is time-consuming-Marks (1998) estimates an extra $10 \%$ of the clinician's time is involved. Secondly, it entails duplication of effort (when two outcome measures co-vary to the extent that one is a fair proxy for another) and it can be wasteful of effort, either when data are collected but not analysed, or when data are collected and analysed but do not inform future treatment. It may be acceptable to absorb the adverse effects of duplication and waste of effort in research programmes, but in already over-stretched routine mental health services this is less possible. Thirdly, the measures themselves may not be 'feasible', or practical for use in routine clinical settings (Slade et al. 1999 b).

Several recommendations flow from these observations. To support the implementation of routine outcome assessment, there is a need to identify the key outcomes to measure in mental health services - unmet need and quality of life have been proposed in this editorial, with therapeutic alliance as an important effect modifier. The development of assessment measures designed specifically for routine clinical use should be prioritized - there should be a moratorium on the development of further research-based assessments. Dedicated interviewers are not available 


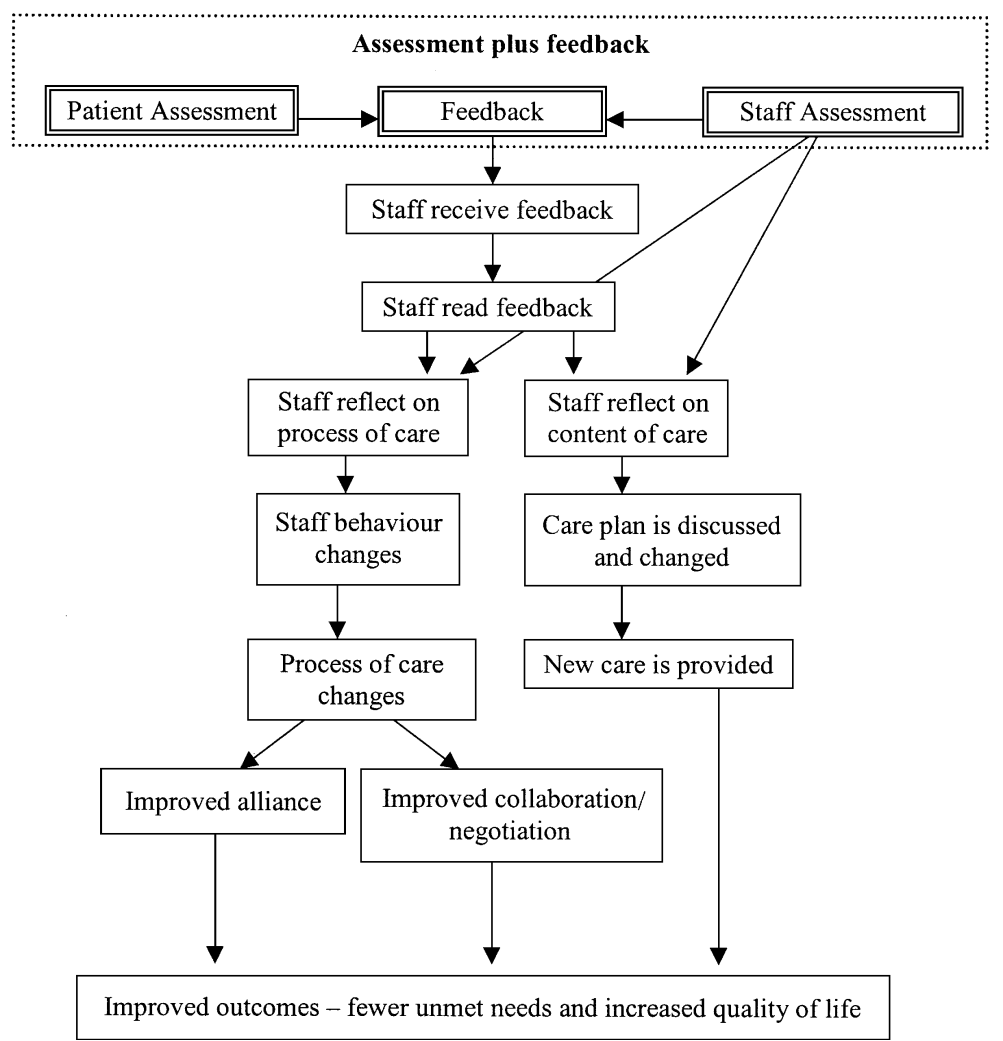

FIG. 1. Mechanisms of action for staff involved in routine outcome assessment and feedback.

in routine settings, so approaches need to be developed to collect outcome data for minimal cost in time and effort to staff and patients - the use of postal questionnaires, the internet and reception staff should all be explored. Audit Departments, which audit structure and process, should be replaced with Outcome Departments to support routine outcome assessment and feedback. Increasing access to and training in information technology should be a priority for all mental health staff, together with the development of an information infrastructure which supports clinical data collection and feedback - in England, the Mental Health Minimum Data Set work would be the obvious platform for this development. Finally, if quality of care is to be maximized, then there needs to be less of a focus on quantity (exemplified by caseload size) and more on promoting and rewarding reflective practice, both at the treatment and the programme level.

\section{CONCLUSION}

In the absence of sound empirical evidence about the relative costs and benefits, there is a risk of ill-conceived and haphazard attempts at routine outcome assessment, which will consume valuable resources, such as staff and patient time, for no evident benefit to the patient. There is some evidence of this happening already-Benjamin and colleagues (1995) reflect that the expectations of American policy-makers and service commissioners are that assessment will "not be "too expensive", not show that the most expensive therapy is best, be easily comprehensible, address the things patients consider important, and, most importantly, save money' (p. 305).

Routine outcome assessment may in itself be of benefit for informing the treatment of patients. Current policy initiatives, the limited evidence base, and the recent development of standardized 
outcome measures specifically intended for routine clinical use (e.g. Wing et al. 1998; Slade et al. 2000) all mean that studies to identify the costs and benefits for patient care of routine outcome assessment are urgently needed.

MIKE SLADE

\section{REFERENCES}

American Psychiatric Association (2000). Handbook of Psychiatric Measures. APA: Washington, DC.

Andrews, G., Peters, L. \& Teeson, M. (1994). Measurement of Consumer Outcome in Mental Health: A Report to the National Mental Health Information Strategy Committee. Clinical Research Unit for Anxiety Disorders: Sydney.

Benjamin, K., Perfetto, E. \& Greene, J. (1995). Public policy and the application of outcomes assessments: paradigms versus politics. Medical Care 33, (Suppl.), AS299-305.

Biggeri, A., Rucci, P., Ruggeri, M. \& Tansella, M. (1996). Multidimensional assessment of outcome: the analysis of conditional independence as an integrated statistical tool to model the relationships between variables. In Mental Health Outcome Measures (ed. G. Thornicroft G and M. Tansella), pp. 207-216. Springer: Berlin.

Burns, T. \& Priebe, S. (1996). Mental health care systems and their characteristics: a proposal. Acta Psychiatrica Scandinavica 94, 381-385.

Clifford, P. (1998). M is for outcome: the CORE outcomes initiative. Journal of Mental Health 7, 19-24.

Dickey, B. \& Azeni, H. (1992). Data watch: impact of managed care on mental health services. Health Affairs 11, 197-204.

Drury, V., Birchwood, M., Cochrane, R. \& Macmillan, F. (1996) Cognitive therapy and recovery from acute psychosis: a controlled trial. British Journal of Psychiatry 169, 602-607.

Fenton, W. S., Blyler, C. R. \& Heinssen, R. K. (1997). Determinants of medication compliance in schizophrenia. Schizophrenia Bulletin 23, 637-651

Gilbody, S. M., House, A. O. \& Sheldon, T. (2002). Routine administration of Health Related Quality of Life (HRQoL) and needs assessment instruments to improve psychological outcome - a systematic review. Psychological Medicine 32, 1345-1356.

Hansson, L., Vinding, H. R., Mackeprang, T., Sourander, A., Werdelin, G., Bengtsson-Tops, A., Bjarnason, O., Dybbro, J. Nilsson, L., Sandlund, M., Sorgaard, K. \& Middelboe, T. (2001). Comparison of key worker and patient assessment of needs in schizophrenic patients living in the community: a Nordic multicentre study. Acta Psychiatrica Scandinavica 103, 45-51.

Harrison, G. \& Eaton, W. (1999). From research world to real world. Current Opinion in psychiatry 12, 187-189.

Huxley, P. (1998). Outcomes management in mental health: a brief review. Journal of Mental Health 7, 273-283.

Keijsers, G. P., Schaap, C. P. \& Hoogduin, C. A. (2000). The impact of interpersonal patient and therapist behavior on outcome in cognitive-behavioural therapy. A review of empirical studies. Behavior Modification 24, 264-297.
McCrone, P. \& Strathdee, G. (1994). Needs not diagnosis: towards a more rational approach to community mental health resourcing in Britain. International Journal of Social Psychiatry 40, 79-86.

Marks, I. (1998). Overcoming obstacles to routine outcome measurement. British Journal of Psychiatry 173, 281-6.

Martin, D. J., Garske, J. P. \& Davis, M. K. (2000). Relation of the therapeutic alliance with outcome and other variables: a metaanalytic review. Journal of Consulting and Clinical Psychology 68, 438-450.

Sainfort, F., Becker, M. \& Diamond, R. (1996). Judgments of quality of life of individuals with severe mental disorders: patient selfreport versus provider perspectives. American Journal of Psychiatry 153, 497-502.

Simon, G. E., VonKorff, M., Rutter, C. \& Wagner, E. (2000). Randomised trial of monitoring, feedback, and management of care by telephone to improve treatment of depression in primary care. British Medical Journal 320, 550-444.

Slade, M., Phelan, M. \& Thornicroft, G. (1998). A comparison of needs assessed by staff and an epidemiologically representative sample of patients with psychosis. Psychological Medicine 28, 543-50.

Slade, M., Leese, M., Taylor, R. \& Thornicroft, G. (1999a). The association between needs and quality of life in an epidemiologically representative sample of people with psychosis. Acta Psychiatrica Scandinavica 100, 149-157.

Slade, M., Thornicroft, G. \& Glover, G. (1999b). The feasibility of routine outcome measures in mental health. Social Psychiatry and Psychiatric Epidemiology 34, 243-249.

Slade, M., Powell, R., Rosen, A. \& Strathdee, G. (2000). Threshold Assessment Grid (TAG): the development of a valid and brief scale to assess the severity of mental illness. Social Psychiatry and Psychiatric Epidemiology 35, 78-85.

Stedman, T., Yellowlees, P., Mellsop, G., Clarke, R. \& Drake, S. (1997). Measuring Consumer Outcomes in Mental Health. Department of Health and Family Services: Canberra, ACT.

Thornicroft, G., Strathdee, G., Phelan, M., Holloway, F., Wykes, T., Dunn, G., McCrone, P., Leese, M., Johnson, S. \& Szmukler, G. (1998). PRiSM Psychosis Study: rationale and design. British Journal of psychiatry 173, 363-370.

UK700 Group. (1999). Predictors of quality of life in people with severe mental illness. British Journal of Psychiatry 175, 426-432.

Walter, G., Cleary, N. \& Rey, J. (1998). Attitudes of mental health personnel towards rating outcome. Journal of Quality in Clinical Practice 18, 109-115.

Wing, J., Beevor, A., Curtis, R., Park, S., Hadden, S. \& Burns, A. (1998). Health of the Nation Outcome Scales (HoNOS. British Journal of Psychiatry 172, 11-18. 